to the increased restrictions on smoking in public places. There is little evidence that parents who smoke have achieved meaningful reductions in their children's exposure through limiting when and where they smoke. Complete cessation remains the only option that can be firmly endorsed, not only for parents' own health but also for their children's.

We thank the Imperial Cancer Research Fund for its support for the Nicotine Laboratory at the Medical Toxicology Unit, and Iain Carey for help with statistical analyses

Contributors: MJJ initiated this study, collated and analysed the data, and drafted the paper. EG and $\mathrm{VH}$ were responsible for designing and carrying out the survey field work. $\mathrm{CF}$ and $\mathrm{AB}$ performed the cotinine assays. DGC contributed to the data analysis and to drafting the paper. MJJ is guarantor for this study. Funding: $\mathrm{MJJ}$ and $\mathrm{AB}$ are supported by the Imperial Cancer Research Fund.

Competing interests: None declared.

1 Cook DG, Strachan DP. Health effects of passive smoking-10: summary of effects of parental smoking on the respiratory health of children and implications for research. Thorax 1999;54:357-66.

2 US Centers for Disease Control and Prevention. State-specific prevalence of cigarette smoking among adults, and children's and adolescents' exposure to environmental tobacco smoke-United States, 1996. MMWR Morb Mortal Wkly Rep 1997;46:1038-43.

3 Eriksen W, Bruusgaard D. Smoking behaviour in young families. Do parents take practical measures to prevent passive smoking by the children? Scand J Prim Health Care 1995;13:275-80.

4 Jaakkola N, Ruotsalainen R, Jaakkola JJ. What are the determinants of children's exposure to environmental tobacco smoke at home? Scand J Soc Med 1994:29:107-12.

5 Borland R, Mullins R, Trotter L, White V. Trends in environmental tobacco smoke restrictions in the home in Victoria, Australia. Tobacco Control 1999;8:266-71

6 Goddard E. Smoking among secondary schoolchildren in England in 1988. London: HMSO, 1989

7 Lader D, Matheson J. Smoking among secondary schoolchildren in 1990. London: HMSO, 1991.

8 Thomas M, Holroyd S, Goddard E. Smoking among secondary schoolchildren in 1992. London: HMSO, 1993

\section{What is already known on this topic}

Over the past decade smoking bans in public places have grown

It is not known whether smoking parents have avoided smoking in the home to protect their children

\section{What this study adds}

Cotinine concentrations in non-smoking children in Britain have almost halved from 1988 to 1998

This reduction is accounted for mainly by reductions in exposure in children from non-smoking homes and from a fall in the percentage of parents smoking

9 Bolling K. Smoking among secondary schoolchildren in 1993. London: HMSO, 1994.

10 Diamond A, Goddard E. Smoking among secondary schoolchildren in 1994. London: HMSO, 1995.

11 Jarvis L. Smoking among secondary school children in 1996: England. London: Stationery Office, 1997.

12 Goddard E, Higgins V. Smoking, drinking and drug use among young teenagers in 1998. Vol 1. England. London: Stationery Office, 1999.

13 McNeill AD, Jarvis MJ, West R, Russell MAH, Bryant A. Saliva cotinine as an indicator of cigarette smoking in adolescents. $\mathrm{Br} J$ Addict 1987:82:1355-60.

14 Feyerabend C, Russell MAH. A rapid gas-liquid chromatographic method for the determination of cotinine and nicotine in biological fluids. J Pharm Pharmacol 1990;42:450-2.

15 Thomas M, Walker A, Wilmot A, Bennett N. Living in Britain:results from the 1996 general household survey. London: Stationery Office, 1998.

16 Jarvis MJ, Strachan DP, Feyerabend C. Determinants of passive smoking in children in Edinburgh, Scotland. Am J Public Health 1992;82:1225-9.

17 Jarvis MJ, McNeill AD, Bryant A, Russell MA. Factors determining exposure to passive smoking in young adults living at home: quantitative analysis using saliva cotinine concentrations. Int J Epidemiol 1991;20: 26-31.

(Accepted 14 June 2000)

\title{
Decreasing prevalence of cigarette smoking in the middle income country of Mauritius: questionnaire survey
}

Helen S Cox, Joanne W Williams, Maximilian P de Courten, Pierrot Chitson, Jaakko Tuomilehto, Paul Z Zimmet

\begin{abstract}
Objectives To describe changes in the prevalence of cigarette smoking in the middle income country of Mauritius from 1987 to 1998 , and to relate these changes to legislative and health promotion efforts over the same period.

Design Questionnaire survey.

Setting Mauritius, an island in the Indian Ocean with a population of about 1.2 million (about $70 \%$ south Asian, 2\% Chinese, and 28\% Creole).

Participants Data were obtained from 5072 participants in 1987, 6573 in 1992, and 6281 in 1998. Main outcome measures Prevalence of current smoking in 1987, 1992, and 1998, sales of cigarettes in Mauritius, and information on activities for control of tobacco.

Results Self reported cigarette smoking has been decreasing in Mauritius since 1987, with the largest decrease between 1987 and 1992. From 1987 to 1998
\end{abstract}

smoking prevalence decreased by $23 \%$ in men and $61 \%$ in women. Smoking decreased across all age and ethnic groups and across different levels of income and education. Sales of cigarettes also decreased in line with smoking prevalence.

Conclusions The introduction of cigarette taxes, a limited health promotion programme, and the absence of massive promotional campaigns by the sole tobacco company on Mauritius have led to a striking and continued decrease in smoking prevalence and cigarette consumption on the island.

\section{Introduction}

Over the past few decades rates of cigarette smoking have decreased in developed countries following considerable legislative controls on tobacco sales and on advertising and with health promotion efforts. ${ }^{12}$ In contrast, smoking rates have increased in many low and middle income countries as tobacco companies
International

Diabetes Institute Caulfield 3162, Australia

Helen S Cox epidemiologist Joanne W Williams epidemiologist

Maximilian P de Courten

director of research Paul Z Zimmet professor

Non-Communicable Disease Unit, Ministry of Health and Quality of Life Mauritius

Pierrot Chitson director continued over

BMJ 2000;321:345-9 
National Public Health Institute, Helsinki, Finland Jaakko Tuomilehto professor

Correspondence to: H S Cox

helen.cox@ dhs.vic.gov.au switch their efforts towards emerging markets. Of the 1.1 billion people who smoke cigarettes, $80 \%$ live in low or middle income countries, and global estimates show that 82000 to 99000 young people start smoking each day. ${ }^{3}$ Therefore greater attention needs to be directed towards cigarette smoking and the actions of tobacco companies in low and middle income countries.

Smoking rates and changes in rates during the 1980s have been reported from 35 European countries. ${ }^{4}$ Generally, smoking among men decreased by on average $3 \%$ to $4 \%$ over a five year period, except in Beijing, where there was an 11\% increase. Smoking among women increased in about half the populations, predominantly where smoking prevalence was relatively low. Many of these countries have instituted intensive programmes to control tobacco. Limited prospective data exist showing changes in cigarette smoking in rapidly developing or middle income countries.

Mauritius is a middle income country, which in 1998 had a per capita gross national product of US\$3700 (£2233). ${ }^{5}$ Rapid economic development has occurred over the past two decades, with a peak in the mid-1980s. A high prevalence of type 2 diabetes and cardiovascular disease prompted three surveys on non-communicable disease in 1987, 1992, and 1998. We present data on cigarette smoking collected during these surveys and information on tobacco control activities, and we relate these to changes in smoking prevalence.

\section{Participants and methods}

Mauritius is an island in the Indian Ocean, with a population of about 1.2 million, comprising about $70 \%$ south Asian, 2\% Chinese, and 28\% Creole. Three population based surveys were undertaken in 1987 (age range 25-74 years), 1992 (25 years and older), and 1998 (20 years and older); the numbers of participants were respectively 5072 ( $86 \%$ response rate), 6573 $(89 \%)$, and $6281(87 \%)$. Details of the survey methodology have been published previously. ${ }^{6}$ All eligible residents residing in population clusters were invited to participate. In 1987, 10 randomly selected population clusters and a purposely selected area of Chinatown in the capital, Port Louis, were surveyed. Population clusters were selected on the basis of

Table 1 Demographic characteristics of samples from each survey. Values are percentages

\begin{tabular}{lcccccc} 
& $\begin{array}{c}1990 \\
\text { Mauritius } \\
\text { census }\end{array}$ & $\begin{array}{c}1987 \\
\text { complete } \\
\text { sample }\end{array}$ & $\begin{array}{c}1992 \\
\text { complete } \\
\text { sample }\end{array}$ & $\begin{array}{c}1992 \\
\text { independent } \\
\text { sample }\end{array}$ & $\begin{array}{c}1998 \\
\text { complete } \\
\text { sample }\end{array}$ & $\begin{array}{c}1998 \\
\text { independent } \\
\text { sample }\end{array}$ \\
\hline Sex & 49.5 & 46.5 & 45.8 & 45.8 & 43.7 & 43.2 \\
\hline Male & & & & & & \\
\hline Age & 59.3 & 48.7 & 36.8 & 41.5 & 30.4 & 65.7 \\
\hline $20-39$ & 27.2 & 35.8 & 46.1 & 45.9 & 48.0 & 25.4 \\
\hline $40-59$ & 13.6 & 15.5 & 17.1 & 12.6 & 21.6 & 8.9 \\
\hline$\geqslant 60$ & & & & & & \\
\hline Household income & $\mathrm{NA}$ & 41.0 & 45.5 & 43.2 & 36.3 & 29.3 \\
\hline Low & $\mathrm{NA}$ & 54.8 & 49.1 & 50.7 & 47.9 & 53.5 \\
\hline Middle & $\mathrm{NA}$ & 4.2 & 5.5 & 6.0 & 15.8 & 17.2 \\
\hline High & & & & & \\
\hline Religion & 50.6 & 51.8 & 47.9 & 39.6 & 50.4 & 51.0 \\
\hline Hindu & & & & &
\end{tabular}

enumeration areas used in the 1983 census in Mauritius. Three additional clusters were included in 1992. In 1998, Chinatown was not sampled, and the lower age limit was 20. People in the additional clusters, new residents in the original clusters, non-responders from previous surveys, and young people now eligible to participate made up "independent samples" of 2837 in 1992 and 1758 in 1998. Owing to the different sampling strategies in all three surveys, not all previous participants were invited to participate subsequently; $57 \%$ of all the participants took part in more than one survey.

Compared with a 1990 population census, the survey samples were weighted in the middle age group, and more women than men participated in each survey (table 1). Information on household income and ethnicity was unavailable from the 1990 census. The independent samples were, however, similar to the complete samples in 1992 and 1998 for household income, and the proportion of Hindu respondents was similar to the census and across surveys.

Cigarette smoking was assessed through questionnaires administered by an interviewer. Participants were asked whether they were never smokers, ex-smokers, or current smokers and how many cigarettes they smoked per day: fewer than 10, 10-20, or more than 20 . We defined smokers as those reporting current smoking at the time of survey.

We restricted statistical analyses to $\chi^{2}$ tests for differences and for trend, and we analysed data with SPSS 9.0 for Windows. Values for prevalence were standardised for age and sex to the 1990 census population by using the direct method.

\section{Results}

\section{Smoking prevalence}

The prevalence of smoking among Mauritians has decreased dramatically since 1987, with the largest decrease between 1987 and 1992 (table 2). Prevalence rates in the independent sample from each survey were similar. Smoking rates decreased greatly in men (23\%) and women (61\%) between 1987 and 1998. Rates have decreased in all three ethnic groups. The proportion of male smokers who smoked fewer than 10 cigarettes per day increased, whereas those smoking more decreased. Most female smokers smoked fewer than 10 cigarettes per day, with little change across the three surveys (table 3 ).

No major differences in smoking prevalence were found among men by age group in 1987; however, in 1992 and 1998 there were significant trends for reduced smoking prevalence with age $(\mathrm{P}<0.05)$. In women, there were no important associations between smoking and age. Smoking prevalence decreased noticeably in all age groups except in 30-39 year old women. Because there is no consistent relation between smoking and age, reducing the lower age limit to 20 in 1998 should not impact on the change in smoking prevalence observed.

Data on the monthly income of households were used to place individuals into low, middle, or high income groups. In each survey a noticeable gradient was observed with smoking prevalence and income among men, with the highest prevalence in the low income group. Among women this association was 
Table 2 Prevalence of smoking among men and women. Values are numbers (percentages) unless stated otherwise

\begin{tabular}{|c|c|c|c|c|c|c|c|c|}
\hline & \multicolumn{3}{|c|}{ Smoking prevalence in men (\%) } & \multirow{2}{*}{$\begin{array}{c}\text { Reduction } \\
\text { from } 1987 \\
\text { to } 1998 \\
(\%)\end{array}$} & \multicolumn{3}{|c|}{ Smoking prevalence in women (\%) } & \multirow{2}{*}{$\begin{array}{c}\text { Reduction } \\
\text { from } 1987 \\
\text { to } 1998 \\
(\%)\end{array}$} \\
\hline & 1987 & 1992 & 1998 & & 1987 & 1992 & 1998 & \\
\hline \multicolumn{9}{|l|}{ Age } \\
\hline $20-29$ & $225 / 380(59.2)$ & $121 / 239(50.6)$ & $110 / 224(49.1)$ & $17^{*}$ & $42 / 461(9.1)$ & $12 / 284(4.2)$ & $5 / 319(1.6)$ & $82^{*}$ \\
\hline $30-39$ & $453 / 764(59.2)$ & $451 / 886(50.9)$ & $275 / 587(46.8)$ & $21^{*}$ & $45 / 866(5.2)$ & $42 / 1009(4.2)$ & $31 / 779(4.0)$ & 23 \\
\hline $40-49$ & $280 / 483(58.0)$ & $376 / 794(47.4)$ & $382 / 848(45.0)$ & $22^{*}$ & $32 / 499(6.4)$ & 19/905 (2.1) & $38 / 968(3.9)$ & $39^{*}$ \\
\hline $50-59$ & $230 / 396(58.1)$ & $312 / 634(49.2)$ & $201 / 521(38.6)$ & $34^{*}$ & $31 / 437(7.1)$ & $21 / 696(3.0)$ & $14 / 677(2.1)$ & $70^{*}$ \\
\hline$\geqslant 70$ & $35 / 71(49.3)$ & $36 / 100(36.0)$ & $45 / 168(26.8)$ & $46^{*}$ & $12 / 101(11.9)$ & $7 / 178(3.9)$ & $6 / 263(2.3)$ & $81^{*}$ \\
\hline Crude total & $1365 / 2357(57.9)$ & $1428 / 3022(47.3)$ & $1157 / 2746(42.1)$ & $27^{\star}$ & $189 / 2713(7.0)$ & $128 / 3550(3.6)$ & $113 / 3532(3.2)$ & $54^{\star}$ \\
\hline Age adjusted $(95 \% \mathrm{Cl})$ & 58.1 (56.1 to 60.1) & 48.2 (46.5 to 50.0$)$ & 44.8 (42.9 to 46.6$)$ & $23^{*}$ & $7.5(6.5$ to 8.5$)$ & $3.8(3.2$ to 4.5$)$ & $2.9(2.3$ to 3.4$)$ & $61^{*}$ \\
\hline $\begin{array}{l}\text { Independent samples age } \\
\text { adjusted }(95 \% \mathrm{Cl})\end{array}$ & 58.1 (56.1 to 60.1$)$ & 47.4 (44.7 to 50.1$)$ & 47.0 (43.5 to 50.6$)$ & $19^{*}$ & 7.5 (6.5 to 8.5$)$ & 4.5 (3.5 to 5.6$)$ & 2.7 (1.7 to 3.7$)$ & $64^{*}$ \\
\hline \multicolumn{9}{|l|}{ Ethnicity } \\
\hline South Asian & $888 / 1555(57.1)$ & $945 / 2041(46.3)$ & $808 / 1968(41.1)$ & $28^{*}$ & $38 / 1751(2.2)$ & $14 / 2343(0.6)$ & $14 / 2447(0.6)$ & $73^{*}$ \\
\hline \multicolumn{9}{|l|}{ Income } \\
\hline Low & $474 / 729(65.0)$ & $541 / 1029(52.6)$ & $260 / 631(41.2)$ & $37^{\star}$ & $106 / 1331(8.0)$ & 70/1905 (3.7) & $53 / 1574(3.4)$ & $58^{*}$ \\
\hline Middle & $849 / 1512(56.2)$ & $813 / 1759$ (46.2) & $692 / 1511(45.8)$ & $19^{*}$ & $72 / 1246(5.8)$ & $51 / 1404(3.6)$ & $40 / 1401(2.9)$ & $50^{*}$ \\
\hline High & $40 / 113(35.4)$ & $67 / 213(31.5)$ & $194 / 574(33.8)$ & 5 & $5 / 98(5.1)$ & $2 / 139(1.4)$ & 13/391 (3.3) & 35 \\
\hline \multicolumn{9}{|c|}{ Education (years of schooling) } \\
\hline$\overline{0-3}$ & $336 / 498(67.5)$ & $293 / 480(61.0)$ & $183 / 360(50.8)$ & $25^{\star}$ & $57 / 988(5.8)$ & $37 / 1129(3.3)$ & $23 / 894(2.6)$ & $55^{*}$ \\
\hline $4-6$ & $600 / 994(60.4)$ & $638 / 1289(49.5)$ & $477 / 1076(44.3)$ & $27^{\star}$ & $83 / 1160(7.2)$ & $64 / 1537$ (4.2) & $60 / 1483(4.0)$ & $44^{*}$ \\
\hline $7-9$ & $116 / 208$ (55.8) & $129 / 283(45.6)$ & 133/307 (43.3) & $22^{*}$ & $23 / 182(12.6)$ & $14 / 259(5.4)$ & $15 / 308(4.9)$ & $61^{*}$ \\
\hline 10-12 & $276 / 573(48.2)$ & $328 / 828(39.6)$ & $314 / 819(38.3)$ & $21^{*}$ & $24 / 361(6.6)$ & 12/571 (2.1) & 14/746 (1.9) & $71^{*}$ \\
\hline Tertiary & $37 / 84(44.0)$ & $38 / 139$ (27.3) & $48 / 179(26.8)$ & $39^{*}$ & $2 / 24(8.3)$ & $1 / 50(2.0)$ & $1 / 94(1.1)$ & 87 \\
\hline
\end{tabular}

${ }^{*} \mathrm{P}<0.05$ by $\chi^{2}$ analysis.

only noticeable in 1987. The largest percentage decreases in smoking prevalence occurred in the low income group in both sexes. A similar relation of increased smoking prevalence with low education was seen in men but not in women in all surveys. Except in those with a tertiary education, decreases in smoking prevalence were consistent across education levels.

\section{Quitting and starting smoking}

Although questions aimed at separating never and ex-smokers were asked, we think the distinction between these options was not clear in the interview. We believe, however, that current smokers were correctly identified. To identify those quitting and those starting to smoke, data from those participating in at least two surveys were assessed. Quitters were defined as those smoking in one survey and not smoking in a subsequent survey, and vice versa for those starting to smoke. Rates of quitting were relatively high, whereas rates for those starting to smoke were low (table 4). From 1987 to 1992 and 1992 to 1998, women were significantly more likely to quit smoking than men and less likely to start $(\mathrm{P}<0.05)$. No difference was found in the quitting rate in men between the two periods, but the proportion of women quitting reduced from $52 \%$ to $33 \% \quad(\mathrm{P}<0.05)$. The rate of starting smoking increased among women but not among men.

\section{Sales of cigarettes}

Based on sales of cigarettes per person per day since 1987 in Mauritius, there has been a gradual but consistent decline in cigarette consumption (figure). Between 1992 and 1998 the tobacco company gradually withdrew regular sized brands of cigarettes and replaced them with king sized brands, leaving
Mauritius as a $100 \%$ market for buying king size cigarettes.

\section{Taxes and health promotion}

The excise duty on cigarettes increased from $75 \%$ of the ex-factory price in 1988 to $180 \%$ in 1998 , a few months before the 1998 survey (figure). Between 1992 and 1996 the excise was stable at 120\%. In 1987 a health promotion strategy was launched by the Mauritian government, which contained elements directed at quitting smoking, including a general media campaign with radio and television advertisements and talks to targeted high risk groups. After 1992 this programme lost momentum but was resurrected in 1998. Various

Table 3 Quantity of cigarettes smoked. Values are numbers (percentages)

\begin{tabular}{lccc} 
No of cigarettes smoked & $\mathbf{1 9 8 7}$ & $\mathbf{1 9 9 2}$ & $\mathbf{1 9 9 8}$ \\
\hline Men & $(\mathrm{n}=1365)$ & $(\mathrm{n}=1428)$ & $(\mathrm{n}=1158)$ \\
\hline$<10$ per day & $611(45)$ & $652(46)$ & $658(57)$ \\
\hline $10-20$ per day & $575(42)$ & $599(42)$ & $431(37)$ \\
\hline $\mathbf{2 0}$ per day & $179(13)$ & $177(12)$ & $69(6)$ \\
\hline Women & $(\mathrm{n}=189)$ & $(\mathrm{n}=128)$ & $(\mathrm{n}=113)$ \\
\hline$<10$ per day & $144(77)$ & $103(81)$ & $87(76)$ \\
\hline $10-20$ per day & $33(17)$ & $25(19)$ & $23(21)$ \\
\hline 20 per day & $12(6)$ & 0 & $3(3)$
\end{tabular}

Table 4 Rates of stopping and starting smoking. Values are numbers (percentages)

\begin{tabular}{lcc} 
& Men & Women \\
\hline $\mathbf{1 9 8 7}$ to $\mathbf{1 9 9 2}$ & & \\
\hline Started smoking & $34 / 750(4.5)$ & $6 / 1887(0.3)$ \\
\hline Stopped smoking & $198 / 967(20.5)$ & $64 / 123(52.0)$ \\
\hline $\mathbf{1 9 9 2}$ to $\mathbf{1 9 9 8}$ & & $28 / 2342(1.2)$ \\
\hline Started smoking & $57 / 1034(5.5)$ & $24 / 72(33.3)$ \\
\hline Stopped smoking & $174 / 875(19.9)$ &
\end{tabular}




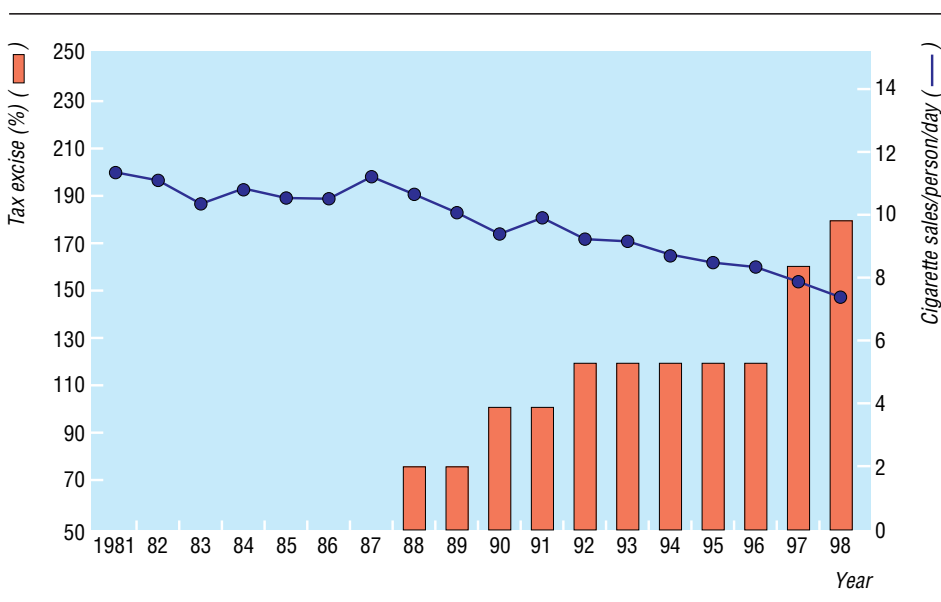

Sales of cigarettes per person per day (line) and tax excise on cigarettes (percentage of ex-factory price) from 1981 to 1998 in Mauritius. Data obtained from Tobacco Board of Mauritius non-government organisations have also provided antismoking programmes in Mauritius throughout the 1990s.

Warnings on the side of cigarette packs were voluntarily introduced in 1976 and legislated in July 1990, along with restrictions on smoking in public places. In April 1993, the legislation was strengthened to include bans on radio and television cigarette advertising and sponsorship of sporting events and social events for minors. Between 1993 and 1998, however, programmes sponsored by the cigarette company continued to be shown on television.

\section{Discussion}

In Mauritius, smoking rates decreased by $23 \%$ in men and $61 \%$ in women between 1987 and 1998 despite the already low rate of smoking in women. Prevalence rates decreased across all ethnic and age groups and income and education levels. A noticeable gradient was observed between smoking prevalence and income in men, with the greatest change across surveys in the low income group. Cigarettes sales in Mauritius have

\section{What is already known on this topic}

Evidence suggests that tobacco companies are now switching their marketing efforts to developing countries as potential emerging markets

Prospective data are, however, lacking on prevalence of cigarette smoking in low and middle income countries

\section{What this study adds}

A major reduction in smoking prevalence has occurred in the middle income country of Mauritius

Legislative changes, including increased taxes on cigarettes, have prompted a reduction in smoking behaviour; this has occurred in the absence of a major promotional campaign by the sole tobacco company

The findings have implications for policies for tobacco control in low and middle income countries also been decreasing in conjunction with smoking prevalence.

\section{Study limitations}

The surveys reported here relied on self reported smoking behaviour. This may result in underreporting of smoking, particularly where there is great social pressure not to smoke. In the Hindu, Muslim, and Chinese populations of Mauritius there is a strong cultural resistance to smoking, particularly among women. It is still customary for middle aged people to refrain from smoking in front of their parents and other elders. The taboo of women smoking is much stronger among Asian families than among the Mauritians of European, African, or mixed descent. However, westernised European, African, and Chinese Mauritian women still refrain from smoking in the street. Smoking prevalence may be underestimated in Mauritius, particularly among women. However, by using the same question to elucidate smoking status across the surveys, any error in reporting should be consistent. Involvement in a health survey may constitute an intervention; however, the independent samples in each of the surveys also showed a substantial decrease in smoking prevalence.

Evidence for smuggling of tobacco products to avoid paying government taxes is emerging throughout the world. Tobacco companies have been implicated in this trade. Increased smuggling of cigarettes could result in an apparent decline in sales of legal cigarettes, as seen in Mauritius. However, in Mauritius, cigarette consumption is primarily of locally produced cigarettes as imported brands are relatively expensive. Unofficial imports occur through tourists, the regular calls of Japanese and Korean fishing fleets, frequent air travel by locals, the proximity of Réunion island, which sells international brands, the existence of duty free cigarettes for inbound passengers, and the occasional rebounding of "shipstores" or diplomatic stocks marked duty free back on the local market. These sources combined would lead to an unimportant increase in the values for total consumption by the local population.

More substantial decreases in smoking prevalence occurred between 1987 and 1992 when increased taxes and antismoking campaigns were first introduced. Between 1992 and 1998, when efforts to control tobacco were diminished, the reduction in smoking prevalence slowed, but decreases in cigarette sales continued. Some of the reduction in sales may represent the switch from regular to king sized cigarettes. Cigarette sales peaked in 1987 in Mauritius after the mid-1980s economic boom. The reduction in smoking prevalence and cigarette sales between 1992 and 1998 may be a consequence of the excise imposed and lessened economic growth over this period.

The reduction in smoking prevalence over 11 years in Mauritius corresponds with that seen in developed countries over much longer periods, ${ }^{7}$ where more intensive and wide ranging programmes of tobacco control have been instituted. In Mauritius, the British-American Tobacco Company has had a virtual monopoly in the cigarette market since Rothmans withdrew in 1980. The amount that the company spends on advertising and promotions is not publicly available, but it is estimated at no more than $£ 250000$ 
annually. This is about 35 US cents (23 pence) per capita and is considerably less than the 18 US dollars per capita spent in the United States. ${ }^{8}$ An analyst of the tobacco industry suggests that British-American Tobacco considers the market in Mauritius saturated, with little potential for increases in volume, and with no new market segments to be opened up there is limited scope for product differentiation. Limited opportunity to break the strong cultural resistance to women smoking is seen. This suggests that Mauritius has avoided massive promotional activity by tobacco companies compared with other developing nations. In the absence of this, any health promotion and legislative efforts, including tax increases, seem to have been more effective and sustained than elsewhere. ${ }^{14}$

Mauritius is a rapidly developing country that has made great gains in tobacco control in the absence of the expensive antismoking campaigns seen in developed countries. It seems that a lack of excessive promotional activity by tobacco companies has led to more effective legislative and health promotion efforts. Increased taxes in conjunction with slower economic growth may have played a major part in reducing smoking behaviour. Reductions in smoking prevalence across income categories support this supposition. These observations support the premise that curbing the efforts of tobacco companies in low and middle income countries is central to initiatives for tobacco control.

We thank the people of Mauritius, Australia, and Finland who have been involved in the planning and conduct of noncommunicable disease research activities in Mauritius since 1987.
Contributors: HSC conceived the rationale for this paper, analysed the data, and wrote the paper. JWW assisted in data analysis and in critical review of the manuscript. MPdeC planned and coordinated the 1998 survey and helped with the analysis and review of the manuscript. PC was involved in the design of the surveys and in initiating tobacco control initiatives in Mauritius. JT designed the survey instrument and reviewed the paper. PZZ, as head of the research group, planned and monitored the conduct of all three surveys and is the guarantor for the paper

Funding: The surveys were supported by a grant from the US National Institutes of Health (No DK-25446) and the Government of Mauritius.

Competing interests: None declared.

1 Hill DJ, White VM, Scollo MM. Smoking behaviours of Australian adults in 1995: trends and concerns. Med J Aust 1998;168:209-13.

2 Garfinkel L. Trends in cigarette smoking in the United States. Prev Med 1997;26:447-50.

3 World Bank. Curbing the epidemic. Governments and the economics of tobacco control. Washington, DC: World Bank, 1999. www.globalink.org/tobacco/ $\mathrm{wb} /$ (accessed 2 Feb 2000)

4 Dobson AJ, Kuulasmaa K, Moltchanov V, Evans A, Fortmann SP, Jamrozik K, et al. Changes in cigarette smoking among adults in 35 populations in the mid-1980s. Tobacco Control 1998;7:14-21.

5 World Bank. Africa region live database. www.worldbank.org/data/ databytopic/ (accessed $23 \mathrm{Feb} 2000$ )

6 Dowse GK, Gareeboo H, Zimmet PZ, Alberti KGMM, Tuomilehto J, Fareed D, et al. High prevalence of NIDDM and impaired glucose tolerance in Indian, Creole and Chinese Mauritians. Diabetes 1990;39:390-6.

7 Centers for Disease Control and Prevention, Office on Smoking and Health. Smoking prevalence among US adults. Tobacco information and prevention source. www.cdc.gov/tobacco/prevali.htm (accessed $11 \mathrm{Feb}$ 2000)

8 Centers for Disease Control and Prevention, Office on Smoking and Health. Domestic cigarette advertising and promotional expendituresUnited States, 1963-1994. Tobacco information and prevention source. www.cdc.gov/tobacco/adv-pro.htm (accessed 2 Feb 2000).

(Accepted 27 June 2000)

\section{Increased mortality among Danish women: population based register study}

Knud Juel

Even at the beginning of the $1950 \mathrm{~s}$, the prevalence of smoking among Danish women was as high as $40 \% .{ }^{1}$ In the 1980s the proportion of men and women who smoked cigarettes in Denmark was almost the same, which is unusual. Data from interviews and questionnaires showed that the proportion of heavy smokers had increased steadily among women over a long period: $1 \%$ (1953), 7\% (1970), 12\% (1980), 15\% (1987), and 18\% (1994). At the beginning of the 1990s, Danish women had the highest prevalence of smoking in the 87 countries in which smoking among women was recorded. ${ }^{2}$ The life expectancy of Danish women is shorter than that of women in other western European countries. ${ }^{3}$ Mortality from lung cancer and chronic obstructive pulmonary diseases among Danish women has increased greatly from the 1960s and is now by far the highest in Europe. ${ }^{3}$ To assess the impact of smoking on mortality among Danish women, we performed a register based study for the period 1951-95.

\section{Methods and results}

We calculated mortality attributable to tobacco use by Peto et al's method. ${ }^{4}$ They compared the death rates from lung cancer in a study population with those of a US group to derive an estimate of smoking rates in the study population (more lung cancer meant more smoking). They assumed that certain relative risks for smoking and important diseases related to smoking applied to all populations. These two sets of assumed statistics were then used to calculate population attributable risks for each of the major causes of death in each population.

Data on deaths and causes of death in Denmark are available in the Cause of Death Register of the National Institute of Public Health, which covers all deaths in Denmark since 1943. The data on deaths in other countries of Europe were derived from the World Health Organization's database.

The figure shows the risk of death among Danish women aged 55-84 since the beginning of the 1950s. The risk of mortality from any cause declined until the start of the 1970s and then increased slightly. In the absence of deaths attributed to smoking, the decline would have continued. The risk of dying of tobacco attributed causes increased steadily, from less than $1 \%$ of all deaths at the beginning of the 1950 s to about $25 \%$ of all deaths 40 years later.

\section{National Institute of Public Health, DK-2100, Copenhagen, Denmark \\ Knud Juel senior researcher kj@dike.dk}

BMJ 2000;321:349-50 